\title{
Effects of Temperature on the Density of Water Based Drilling Mud
}

\author{
EBIKAPAYE, JP \\ Department of Petroleum and Gas Engineering, Delta State University, Abraka, P. M. B. 22, Oleh Campus, Nigeria. E-mail: \\ peretomodejeffery7@gmail.com, Tel: +2348035831365, +234809243661
}

\begin{abstract}
Rheological properties are tested throughout a drilling operation as it is critical in the control and maintenance of rheological properties. This paper investigates the effects of temperature on the density of water based drilling mud. Water based mud was prepared with resistant additives and weighing materials for temperature conditions ranging $28^{\circ} \mathrm{C}, 30^{\circ} \mathrm{C}, 40^{\circ} \mathrm{C}, 50^{\circ} \mathrm{C}, 60^{\circ} \mathrm{C}, 70^{\circ} \mathrm{C}$ and the densities at these temperature ranges was determined. The experimental data obtained supports the idea that mud density being a rheological property decreases $(8.85 \mathrm{ppg}-8.49 \mathrm{ppg})$ with increase in temperature $\left(28^{\circ} \mathrm{C}\right.$ to $\left.70^{\circ} \mathrm{C}\right)$.This is as a result of the mud contents becoming degraded upon addition of heat at higher temperatures.
\end{abstract}

DOI: https://dx.doi.org/10.4314/jasem.v22i3.20

Copyright: Copyright (c) 2018 Ebipakaye. This is an open access article distributed under the Creative Commons Attribution License (CCL), which permits unrestricted use, distribution, and reproduction in any medium, provided the original work is properly cited

Dates: Received: 09 December 2017; Revised: 27 January: 2018; Accepted: 12February 2018

Keywords: Temperature; drilling mud; Hydrostatic pressure; Bentonite

Drilling mud (fluids) are complex heterogeneous fluids, consisting of several additives that are employed in drilling of oil and natural gas wells since the early 1900. The original use of the drilling mud was to remove cuttings continuously. Progress in drilling engineering demanded more sophistication from the drilling mud. Drilling mud selection is a function of the behaviour of the formation to be drilled (Johannes, 2011; Joel et al, 2012). As the drilling mud evolved, their design changed to have common characteristic features that aid in safe, economic and satisfactory completion of a well. In addition, amongst other functions, drilling mud is also now required to Assist in cementing and completion of well, Seal the formation pores by forming low-permeability filter cake to prevent inflow of formation fluids into the well (Growcock and Harvey, 2005; Darley and Gray, 1988):

In order to ensure proper functionality of drilling mud, adequate understanding of the key factors governing the selection of the mud is critical for appropriate drilling mud selection. The behavior of the drilling mud under high temperature and high pressure is extremely important for drilling geothermal wells and for drilling deep wells. A systematic examination of rheological properties (viscosity, Fluid loss, mud density, gel strength, $\mathrm{pH}$, and yield point and cake thickness) of mud density under the effect of temperature is the main subject of this research.
Temperature increases with depth as we drill through or within deep formations; therefore, producing from such high temperature zones involves several challenges to petroleum engineers in terms of drilling, completion, and production. Among these challenges is the alteration of the rheological properties of drilling mud. Thus, a thorough experimental study was conducted to determine the effect of this high temperature effect on the mud density so as to determine the mud characteristics at different temperature range in order to get the best knowledge of how to minimize this effect for a successful drilling, completion and production from such zone. Density of drilling mud is defined as weight per unit volume. It is expressed in field units as pounds per gallon (lb/gal). It is an important parameter which is controlled during a drilling operation. In order to prevent formation fluids from flowing into the well bore and to seal the well bore with a thin, low-permeability filter cake; the density of drilling fluid must exceed the pore pressure of the formation (Darley and Gray, 1988). However, the mud column density should not be high enough to cause formation fracture. Numerous weighing agents can be used to increase mud density to desired value using high specific gravity solid, such as barite, hematite, galena, calcium carbonate, and ilmenite, with Barite as the most widely used weighing agent. The objective of this paper is to present a laboratory investigation on the effects of temperature on water based drilling mud density. 


\section{MATERIALS AND METHOD}

Materials: Nigerian Bentonitic clay obtained from Ozoro in the Isoko South Local Government Area of Delta state was used for this investigation. Barite, carboxyl methyl cellulose $(\mathrm{cmc})$, distilled water (350ml)

Apparatus: Measuring cylinder $\left(\mathrm{EX} 20^{\circ} \mathrm{c} 500 \mathrm{ML} \pm\right.$ $5 \mathrm{ml}$ ), digital weighing balance, mixer cup, mud mixer machine (REG no 402260 VICCO), drier box (DHG- 9053$)$, thermometer $\left(-20\right.$ to $\left.100^{\circ} \mathrm{c}\right)$, mud balance (model 140 Baroid testing equipment), $\mathrm{pH}$ meter (digital pH meter), digital stop watch, beaker, fann filter press (series 300), spatula and rheometer.

Mud preparation and experimental procedures: This involves the laboratory preparation of water based mud that is necessary to obtain a level of resistant additives and weighing materials of high temperature (HT) condition, so as to determine the characteristics of the mud at different temperature range. Here, using a digital weighing balance we weighed the bentonite clay (21g), barite (5g), Carboxyl methyl cellulose $(\mathrm{cmc})(6 \mathrm{~g})$ to treat the clay and poured in a mixer cup, and then $350 \mathrm{ml}$ of distilled water as the continuous phase was measured with a measuring cylinder (ml) and added to the mixture in the mixer cup. The mixer cup was attached to a mixer machine with the aid of a clip and the mixer machine was connected to a power source for powering. The powered mixer machine helped to properly mix or blend the mixture so as to obtain a smooth mixture of the mud. The prepared mud and was placed in a drier box and heated for some hours so as to obtain the highest required temperature for the test.

Mud weight determination with temperature effect: Before beginning this procedure, the calibration is checked (calibration mark provided on scale for fresh water, $8.33 \mathrm{lb} / \mathrm{gal}$ or $1.0 \mathrm{~S} . \mathrm{G}$.), and made sure that the cup is clean and dry. The lid from the mud cup is removed and filled with the heated mud till it overflows. If air bubbles were trapped in the mud, it is tapped briskly on the side until air bubbles are removed.

The temperature of the heated mud was tested using a thermometer, and immediately replaced the lid on the cup and rotated it until it was firmly seated; made certain that some mud squeezed out the vent hole in the lid. Excess mud is washed and wiped from the exterior of the mud balance, covering the vent hole, and then dried the balance. The balance is placed on its base with the knife edges on the fulcrum rest. The rider is moved until the beam was balanced making sure that the spirit level bubble is on the center line.
The mud weight and hydrostatic pressure or mud gradient at the edge of the rider nearest to the fulcrum was read. The instrument is then clean and replaced. This process was repeated for a maximum temperature of $70^{\circ} \mathrm{C}$ and repeated for a temperature drop of 70,60,50,40,30, and $28^{\circ} \mathrm{c}$ (room temperature). The hydrostatic pressure exerted by a static mud column depends on both the density and the depth. The hydrostatic pressure at depth $\mathrm{D}$, for a column of mud having density $(\rho)$ is derived by using following equation.

$\mathrm{P}=0052 \rho \mathrm{D}$

Where $\mathrm{P}=$ Hydrostatic pressure (psi), $\rho=$ Mud Density (lb/gal), D = Depth (ft)

All materials present in mud contribute to its density. The resulting mud mixture from all the additives and water is assumed to be ideal; hence the total volume is equal to sum of the component volumes (Bourgoyneet al., 1986).

$\mathrm{V}_{\mathrm{t}}=\mathrm{V}_{1}+\mathrm{V}_{2}+\mathrm{V}_{3}+\ldots . \mathrm{V}_{\mathrm{n}} \ldots \ldots$ (2)

Where, the volume $V i$ of given additives, having density $\rho_{i}$ and sample mass of $m_{i}$ is given by following equation

$V_{i}=\frac{m_{i}}{\rho_{i}}$

Hence, the resulting mud density can be computed using following expression

$\rho=\frac{m_{1}+m_{2}+m_{3}+m_{n}}{V_{1}+V_{2}+V_{3}+\ldots . V_{n}}$

\section{RESULTS AND DISCUSSION}

Furtherance on the mud weight determination and the experiment described, the readings of the mud weight determined using the mud balance and the corresponding temperature readings gotten, using a thermometer were recorded in a tabulated format.

Using the mud balance the readings of the mud weight were recorded after the mud balance was made to balance at the knife edge by adjusting the beam and the readings were recorded in pounds per gallon (ppg) and at the corresponding temperature readings. It was noted that prior to each measurement recorded; during the experiment air interruption was prevented so as to avoid error due to parallax in order to obtain accurate results. The mud weight readings recorded from the mud balance were subsequently plotted against the corresponding temperatures as presented in figure1. 


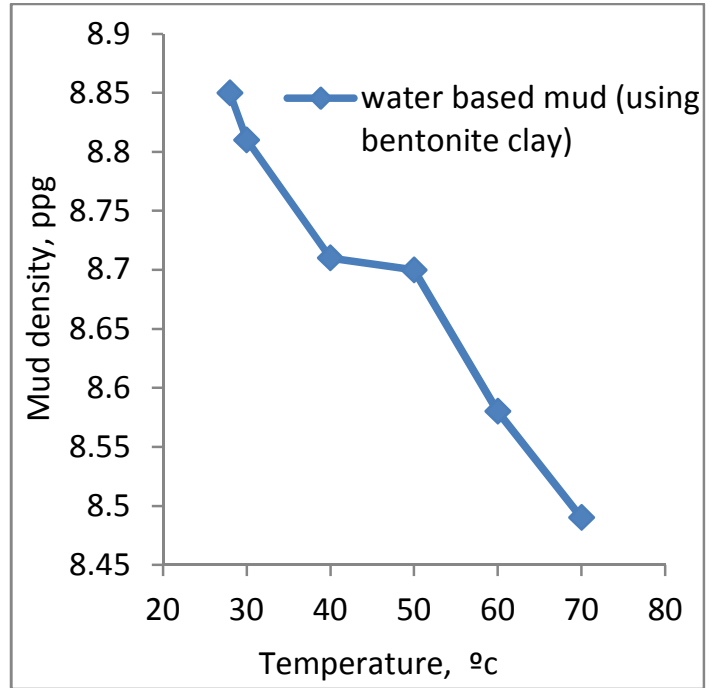

Fig. 1: Plot of density against temperature (water based mud, using bentonite clay)

At temperatures of $40^{\circ} \mathrm{C}$ and $50^{\circ} \mathrm{C}$, the densities 8.71 and $8.70 \mathrm{ppg}$ are almost the same or uniform. This is shown in Fig.1. This is due to the differences in temperature and heat energy required to dissipate bonds, which vary with fluid properties (i.e. the continuous phases).Drilling through high temperature zone in a formation with water based mud constitutes a problem of significant proportion in the petroleum industry. The associated effects of this problem include overall decrease and loss in the mud properties. From the results of the experiments carried out, temperature was found to have undoubted huge effect. The mud density being a rheological property decreases with increase in temperature, this is as a result of the mud contents being heated at higher temperature and they become degraded; hence contributing to the decrease in mud density.

Conclusion: From the results obtained, it can be generally concluded that temperature has an undoubted huge effect on drilling mud property as drilling through high temperature zone in a formation with water based mud constitutes a problem of significant proportion in the petroleum industry. This is as a result of the significant decrease and loss in the mud density.

\section{REFRENCES}

Annudeep Singh Dhiman, (2012). Rheological properties \& corrosion characteristics of drilling mud additives. Dalhousie University Halifax, Nova Scotia, page 22.

Azar, J; Samuel, GR (2007). The Effect of Drill Fluid $\mathrm{pH}$ on Drill Pipe Corrosion Fatigue Performance.Drilling Engineering. 14-17.

Bourgoyne J.;Millheim, AT;Chenevert, ME; Young Jr., F (1986), Richardson TX. Applied Drilling Engineering; Society of Petroleum Engineers Journal12 (8) 60-63.

Clark, EP (1995). Drilling Mud Rheology and the API recommended Measurements.Society of Petroleum Engineers Journal 9 (2), 105-122.

H. C. H. Darley; George R. Gray; RyenCaenn(1988).Composition and Properties of Drilling and Completion Fluids. Page 155169.

Growcock, F; Harvey, T (2005). Drilling Fluids Processing Handbook. pp 67-94

Maglione,R;Robotti, G;Romagnoli, R (2000). In-Situ Rheological Characterization of Drilling Mud. Society of Petroleum Engineers Journal. 5 (4), 377-386.

MahmoodAmani; Mohammed Al-Jubouri (2012). Energy Science and Technology. 4 (1), 27-33.

Omotioma, M; Ejikeme PCN; Ume, JI (2015). Improving the Rheological Properties of Water Based Mud with the Addition of Cassava Starch. IOSR Journal of Applied Chemistry(IOSR-JA).

Ronald, P; Bernhard, BS (1981). Rheological properties of high-temperature drilling fluids, page 11-12. 